\title{
Litigios individuales y conflictividad colectiva. El mundo del trabajo mirado desde un estrado laboral de provincia. Santa Fe, 1949-1955
}

Individual litigation and collective conflict. Focusing the world of labor from a provincial labor court. Santa Fe, 1949-1955

Natacha Bacolla CONICET Argentina

DOI: https://doi.org/10.25032/crh.v5i9.11

Recibido: 30/04/2019

Aceptado: 26/09/2019

Resumen. El artículo indaga desde un estudio de caso, el del Tribunal Laboral N N. ${ }^{\circ} 1$ con sede en la ciudad de Rosario, los modos en que trabajadores y patrones hicieron uso de dicha institución durante los años peronistas, y sus estrategias de intervención en una instancia que, aunque se proponía resolver los conflictos individuales derivados de la relación laboral, impactaba en términos colectivos en una arena de disputa que daba cuerpo a una frontera de clase. En primer lugar, se describen las características de la regulación laboral argentina y sus particularidades en la provincia de Santa Fe. En segundo lugar, se analizan, a partir de las sentencias producidas en el tribunal rosarino, los modos en que el cariz colectivo de las disputas en el mundo del trabajo impregna el proceso judicial de causas individuales; focalizando en un nudo de conflictividad particular: aquellas presentadas por la aplicación de los convenios colectivos de trabajo.

Palabras clave: Regulaciones estatales; Fuero del Trabajo; Peronismo; conflictividad laboral.

Summary. The article investigates from a case study, the Labor Court No. 1 based in the city of Rosario, the ways in which workers and employers made use of said 
institution during the Peronist years, and their intervention strategies in an instance that, although it was intended to resolve individual conflicts arising from the employment relationship, it had a collective impact in a dispute arena that gave rise to a class frontier. In the first place, the characteristics of the Argentine labor regulation and its peculiarities in the province of Santa Fe are described. Secondly, the article analyzes the ways in which the collective nature of the disputes in the labor world permeates the judicial process of individual cases; focusing on a particular conflict knot: those presented by the application of collective labor agreements.

Keywords: State regulations; Work Jurisdiction; Peronism; labor conflict.

\section{Introducción}

«¿Justicia? La justicia se encuentra en el otro mundo. En este lo que hay son leyes».1

En los últimos años la historia social del trabajo y la historia del Estado han dado fructíferos marcos y categorías para abordar la compleja dinámica de construcción de aquello que desde finales del siglo XIX se ha llamado «la cuestión social». No solo focalizando en las herramientas ensayadas para actuar sobre ella, sino en el modo en que se constituían los actores-trabajadores, patrones y también expertos-, en su interacción con las normas y las prácticas institucionales que erigirían paulatinamente al Estado como mediador. ${ }^{2}$ En Argentina dicho proceso tuvo un punto de inflexión sin duda en la creación largamente postergada de tribunales del trabajo que corporizarán el «nuevo derecho», con el aditamento de la fuerte carga que significó que su origen estuviera asociado a la experiencia peronista. Estas nuevas instituciones recién han comenzado a abordarse en la historiografía Argentina, como otra arista para observar la articulación entre Estado y mundo del trabajo, desplazando el más recurrente foco de los estudios sobre los años del primer

\footnotetext{
${ }^{1}$ William Gaddis, Frolic of His Own, New York, Paperback, 1995, 12.

2 Entre una extensa bibliografía: Mirta Lobato y Juan Suriano (comps.), La sociedad del trabajo. Las instituciones laborales en la Argentina (1900-1955), Buenos Aires, Edhasa, Karina Ramaciotti, «Presentación al dossier: Ley de Accidentes de Trabajo y Enfermedades profesionales», Estudios Sociales, $\mathrm{N}^{\circ}$ 49, Santa Fe, UNL, 2015, Eduardo Zimmermann, Los liberales reformistas. La cuestión social en la Argentina, 1890-1916, Buenos Aires, Sudamericana, 1995, Juan Suriano (comp.), La cuestión social en Argentina 1870-1943, Buenos Aires, Editorial La Colmena, 2000, Daniel Lvovich y Juan Suriano, Las políticas sociales en perspectiva histórica. Argentina 1870-1952, Buenos Aires, Prometeo, 2006, Mariano Plotkin y Eduardo Zimmermann (comps.), Saberes del Estado, Buenos Aires, Edhasa, 2012.
} 
peronismo en torno a las instancias administrativas, partidarias, las relaciones con el movimiento sindical, las huelgas o las discursividades políticas. ${ }^{3}$ Como ha señalado Andrés Stagnaro, la contienda en la justicia laboral permite adentrarse en otro tipo de conflictividad, diferente a la que ocupa la calle o se manifiesta en la huelga, que además de estar institucionalizada «... expresa el enfrentamiento entre el capital y el trabajo de manera directa con eje en el valor de la mano de obra [...] pero sobre todo como una pelea por la obtención y ampliación de derechos, y control patronal de los establecimientos».4Sumado a esto, y a diferencia de los canales de mediación propuestos por la vía administrativa, aquellas de carácter judicial abordarían los diferendos derivados de la relación laboral no en su carácter colectivo o corporativo, sino en tanto que litigios individuales. En este registro los tribunales del trabajo, en su funcionamiento cotidiano ofrecen, además de un mirador diferente para analizar el rol mediador del Estado o el conflicto, un corpus estratégico para situar el papel de lo social en las relaciones discursivas que construyen mecanismos de identificación en el mundo del trabajo. Las prácticas judiciales y el corpus de leyes sobre los que se expiden, como señalaba E.P. Thompson en sus estudios sobre el siglo XIX inglés, expresan no solo nociones de justicia socialmente construidas sino además constitutivas de las identidades de clase. $5 \mathrm{Y}$ en este sentido los archivos judiciales ofrecen un campo de comprobación, en palabras de otro historiador social británico, Gareth Stedman Jones, de la propia complejidad de las operaciones de construcción lingüística de «las experiencias» de clase, y la percepción del conflicto, confluyentes en lo que denomina «lenguajes de clase». ${ }^{6} \mathrm{En}$ ese sentido poco conocemos sobre el impacto de estos espacios en sus dos principales dimensiones: como poderosas

3 Entre otros trabajos pueden mencionarse: Juan Manuel Palacio, La justicia peronista. La construcción de un nuevo orden legal en Argentina, Buenos Aires, Siglo Veintiuno Editores, 2018, Andrés Stagnaro, Y nació un derecho. Los tribunales del trabajo en la provincia de Buenos Aires, Buenos Aires, Biblos, 2018, Agustín Nieto, «Conflictividad obrera en el terreno de la justicia laboral. La experiencia de las obreras/os del pescado, 1950-1955», en AA.VV., Los puertos y su gente: pasado, presente y porvenir, Mar del Plata, GESmar, 2011, 117-128, Natacha Bacolla, «El lugar del Estado en la construcción de identidades políticas. Regulaciones del trabajo y la construcción del peronismo en la provincia de Santa Fe», en Revista de Historia Americana y Argentina, vol. 53, No 2, 2018, 161-191. A escala americana: León Fink y Juan Manuel Palacio (eds.), Labour Justice across the Americas, Illinois, University of Illinois Press, 2018.

4 Andrés Stagnaro 201819.

5 Entre otras obras del autor significativas al respecto: E. P. Thompson, Costumbres en común, Barcelona, Crítica, 1995 y Los orígenes de la ley negra. Un episodio de la historia criminal inglesa, Buenos Aires, Siglo Veintiuno Editores, 2010.

${ }^{6}$ Gareth Stedman Jones, Lenguajes de clase. Estudios sobre la historia de la clase obrera inglesa, Madrid, Siglo Veintiuno Editores, 1989. 
herramientas de construcción de identidades; a la par que de disciplinamiento y de encauzamiento de la conflictividad social.

En este marco el presente trabajo indaga de forma exploratoria y desde un estudio de caso, el del Tribunal Laboral $n .^{\circ} 1$ con sede en Rosario - segunda ciudad argentina de mayor crecimiento industrial en el período-, los modos en que trabajadores y patrones hicieron uso de dicha institución judicial durante los años peronistas, y sus estrategias de intervención en una instancia que, aunque se proponía resolver los conflictos individuales derivados de la relación laboral, impactaba en términos colectivos en una arena de disputa que daba cuerpo a una frontera de clase. El artículo se detiene en primer lugar en las características que asumió la regulación laboral argentina y en sus particularidades en la provincia de Santa Fe. En segundo lugar, focaliza a partir de las sentencias producidas en esos primeros años de funcionamiento del tribunal rosarino, los modos en que el cariz colectivo de las disputas en el mundo del trabajo impregna, a pesar de la letra de la ley, el proceso judicial. Deteniéndose para ello en un nudo de conflictividad particular: aquel relativo a la aplicación de los convenios colectivos de trabajo.

\section{Fuero laboral e instancias administrativas de resolución de conflictos en el mundo del trabajo: entre provincia y nación 7}

Las preocupaciones por la regulación del mundo del trabajo reconocían ya para la década del cuarenta en el país un largo recorrido. Aunque, como ha señalado Juan Manuel Palacio, la actuación de la flamante Secretaría de Trabajo y Previsión (STyP) y las circunstancias de la implementación de la justicia del trabajo fueron «... motivo suficiente para otorgarle paternidad al naciente peronismo sobre este nuevo fuero». ${ }^{8}$ Desde sus primeras actuaciones como responsable de la secretaría, Perón se ocuparía de remarcar la novedad de sus intervenciones:

\footnotetext{
7 Los aspectos abordados someramente en este apartado han tenido como insumo un artículo de mi autoría enfocado en estas aristas del proceso: «El lugar del Estado en la construcción de identidades políticas. Regulaciones del trabajo y la construcción del peronismo en la provincia de Santa Fe», en Revista de Historia Americana y Argentina, vol. 53, $\mathrm{N}^{\circ} 2, \mathrm{UNCu}$, Mendoza, segundo semestre de 2018.

Disponible

en

http://revistas.uncu.edu.ar/ojs/index.php/revihistoriargenyame/article/view/1644.

8 Juan Manuel Palacio, «El grito en el cielo. La polémica gestación de los tribunales del trabajo en Argentina», en Estudios Sociales, N 48 , 1. ${ }^{\text {er }}$ semestre de 2015, Santa Fe, UNL, 61.
} 
Antes del 17 de noviembre de 1943 la legislación del trabajo no solo era escasa sino que su cumplimiento quedaba librado a la buena o mala predisposición patronal o a la fuerza de que dispusieran los sindicatos obreros para imponer su respeto. El Estado se encontraba ausente, puesto que el Departamento Nacional del Trabajo [DNT] y sus similares de las provincias, carecían de suficiente autoridad efectiva y de los recursos legales que les permitieran defender los legítimos derechos del trabajador [...] para modificar sustancialmente esa situación se creó la Secretaría de Trabajo y Previsión. 9

La construcción de esta imagen de ruptura en relación con la acción estatal en materia de legislación social, implicaba poner en primer plano la faz represiva adquirida precedentemente por las respuestas a la conflictividad laboral, y a su vez relativizar el impacto del conjunto legislativo e institucional previo. Dispositivos que habían emergido al calor de diversas empresas: desde aquellas delineadas por el «reformismo liberal» frente a la «cuestión social», las iniciativas socialistas, las acciones del radicalismo luego, y que con la conjunción de crisis política y económica acaecida en la década del treinta, habían alimentado una profundización del intervencionismo estatal, en un contexto de prácticas políticas fraudulentas. ${ }^{10}$ Por otra parte dejaba un silencio respecto de la conformación de hecho de una justicia laboral antes de su existencia propiamente dicha, emanada de las instancias de conciliación y arbitraje tanto del DNT como de los organismos locales, y la jurisprudencia de los tribunales civiles y comerciales. ${ }^{11}$

Un componente importante de estos nuevos roles del Estado nacional, como ha demostrado una extensa historiografía, había ido constituyéndose en respuesta a las transformaciones experimentadas por la economía argentina luego de la Gran Guerra. Dichos cambios se caracterizaron por incorporar paulatinamente el desarrollo del sector industrial al principal rubro económico nacional, la producción

\footnotetext{
${ }_{9}$ Crónica Mensual de la Secretaría de Trabajo y Previsión, año II, No 9, enero de 1945, 55.

10 $\mathrm{Al}$ respecto hemos citado algunos trabajos de referencia en nota 2.

${ }^{11}$ Cf. entre otros trabajos sobre diversos aspectos de esta justicia laboral antes de la conformación del fuero: Juan Manuel Palacio, La paz del trigo, Buenos Aires, Edhasa, 2013, Line Schojölden, Suing for Justice: Labor and the Courts in Argentina, 190o-1943, Berkeley, Tesis de Doctorado, Universidad de California, 2002, Germán Soprano, «El Departamento Nacional del Trabajo y su Proyecto de Regulación Estatal de la Relación Capital-Trabajo en Argentina: 1907-1943», en José Panettieri (comp.), Argentina: trabajadores entre dos guerras, Buenos Aires, Eudeba, 2000, Luciano Barandiarán, "Las estrategias de los trabajadores rurales ante la justicia: Azul, 1930-1945», en Anuario del Centro de Estudios Históricos Profesor Carlos A. Segreti, Córdoba, vol. vII, 2007, Karina Ramacciotti, «De la culpa al seguro. La ley de accidentes de trabajo, Argentina 1915-1955, en Revista Mundos do Trabalho, vol. 3, $\mathrm{N}^{\circ}$ 5, enero-junio de 2011, 266-284.
} 
agro-ganadera. ${ }^{12}$ Además de innovaciones en la estructura productiva y la activación de la movilización obrera en los sectores vinculados, el contexto estimuló una respuesta estatal con cierta originalidad, que buscaría no solo la institucionalización del conflicto sino también el desarrollo de mecanismos organizativos del mercado de trabajo. ${ }^{13}$ Las provincias de la región pampeana y litoral fueron los principales ámbitos de este proceso dentro del conjunto nacional. En el caso de Santa Fe entre 1935 y 1946 los puestos de trabajo en la industria se duplicaron, pasando de 44.184 a 94.673, para llegar a sumar en 1954 109.368. Algunas ciudades de la región acusaron mayor impacto, en especial Rosario; la cual además de activo centro portuario de un rico hinterland rural se convirtió en la segunda área industrial urbana del país. ${ }^{14} \mathrm{~A}$ su vez, las dinámicas del mercado internacional generaron una profunda reestructuración del sector primario en la zona, fortaleciendo el desarrollo ganadero por sobre el agrario, con las consiguientes consecuencias sociales, en cuanto a la expulsión de mano de obra y arrendatarios ocupados en el sector. ${ }^{15}$ Estos factores explican en parte la centralidad que a nivel de la agenda pública provincial adquirió el problema de la regulación del mercado laboral. Expresado no solo en el ámbito de las instituciones estatales sino también en las discusiones académicas, a lo largo de la década del treinta. ${ }^{16}$

El estado provincial avanzó en diversos registros fortaleciendo sus capacidades de intervención para reglar el mundo del trabajo. Proceso que se desarrolló desde las gobernaciones de signo radical de la década del veinte a la llegada del peronismo, con

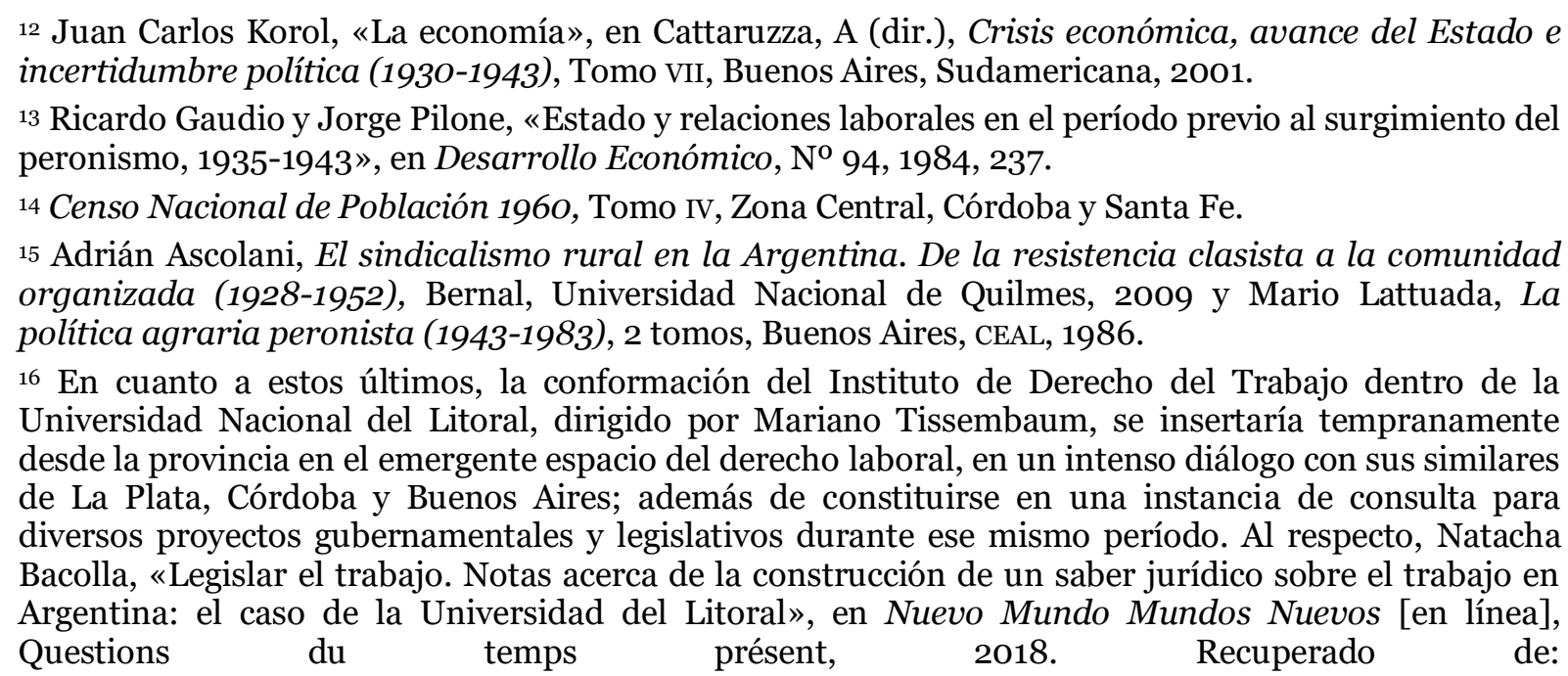
http://journals.openedition.org/nuevomundo/71889. 
tres inflexiones importantes. ${ }^{17}$ En primer lugar, la creación del Departamento Provincial del Trabajo (DPT), en 1927 -bastante tardíamente en relación conotros casos provinciales-,acompañada por la actualización de la legislación laboral siguiendo la pauta nacional y un proceso de centralización de la capacidad de inspección, mayormente con anterioridad en manos de las instancias comunales y municipales. Una segunda inflexión tuvo lugar, durante el gobierno demócrata progresista a inicios de la década del treinta, con la sanción de la Ley 2426 de Régimen Legal del Trabajo, que incorporaba mecanismos de conciliación y arbitraje -que solo quedaron en la letra- y un proceso de descentralización de la agencia en el territorio provincial. Finalmente, en la segunda mitad del decenio, con el radicalismo antipersonalista controlando el poder local, la provincia mantendría la ley, reorientando su implementación en cuestiones que limitaban la descentralización, pero sosteniendo el núcleo duro de la norma que depositaba en el DPT el peso principal de la acción estatal en materia laboral: con capacidad de arbitraje, control, vigilancia, y habilitación de personería jurídica a las asociaciones gremiales tanto obreras como patronales. Como señalan algunos trabajos, las actuaciones de esta agencia dejarían un saldo favorable en cuanto al crecimiento de las capacidades de intervención del Estado provincial en relación con la institucionalización y mediación de los conflictos laborales; que sin embargo seguirían conviviendo con lógicas represivas. ${ }^{18}$ La Ley 2952, que en 1941 modificaría la organización ministerial de la provincia, traería consigo como principal punto la creación de un Ministerio de Salud Pública y Trabajo (MSPyT). Si bien este puso su principal atención en el área de sanidad y asistencia social, generó también una centralización de la regulación laboral, siendo sus agencias ocupadas en buena parte por cuadros crecientemente

17 Hemos focalizado sobre estos temas en «Nuevas capacidades estatales para una sociedad transformada. Instituciones y políticas sanitarias en la provincia de Santa Fe primera mitad del siglo XX», en Trabajos y Comunicaciones, $\mathrm{N}^{\circ}$ 44, UNLP, 2016, «Política, administración y gestión en el peronismo santafesino, 1946-1955", en D. Macor y C. Tcach (eds.), La invención del peronismo en el interior del país, Santa Fe, Ediciones UNL, 2003, «Debates, prácticas políticas y reforma institucional en la entreguerras. Un análisis desde el caso santafesino», en M.S. Leoni y M.M. Solís Carnicer, $L a$ política en los espacios subnacionales. Provincias y territorios en el nordeste argentino (1880-1955), Rosario, Prohistoria, 2012.

${ }^{18}$ En términos generales Susana Piazzesi señala el incremento de mediaciones realizadas -que, de 113 en 1938, pasarían a contabilizar 230 en 1941, y las buenas relaciones con la Federación Santafesina del Trabajo; mientras los estudios de Adrián Ascolani sobre el mundo rural señalan una tendencia similar. La Federación Santafesina del Trabajo fue creada en 1937, confluyendo en ella tanto sindicatos urbanos como rurales. Al año 1941 contaba con 45.00o adherentes y 15.000 cotizantes. Estaba adherida a la CGT. Al respecto: Organización Sindical, Publicación del Departamento Nacional del Trabajo, 1941; también Ascolani, 2009 y Susana Piazzesi, Conservadores en provincia. El iriondismo santafesino, 1937-1943, Santa Fe, Ediciones UNL, 2009. 
influidos por la doctrina social católica. De este modo, al momento del golpe militar de 1943, la experiencia conservadora había logrado consolidar un conjunto de herramientas de intervención social que, si bien se conjugaban con lógicas de control y ejercicio clientelar en un marco político restrictivo, contribuyeron a instalar el rol arbitral del Estado provincial, a la par que organizar a los actores constitutivos de las relaciones laborales.

Las sucesivas intervenciones designadas por el gobierno de facto y, en particular, la elite estatal que se consolidó luego de 1944 - con el alejamiento de los sectores militares de tendencia más nacionalista- preservaron estas agencias estatales imprimiéndole nuevos contenidos y adaptándolas a los marcos regulatorios vigentes a nivel nacional. estos se habían modificado a partir de la creación de la Secretaría de Trabajo y Previsión (STyP) en noviembre de 1943, iniciando un proceso de concentración de un conjunto de dependencias que, excediendo el ámbito laboral, constituyeron herramientas institucionales permanentes que darían al Estado nacional la capacidad de operar sobre diversos aspectos y problemas sociales. ${ }^{19} \mathrm{La}$ acción de Juan Domingo Perón en la misma, en los años previos a su llegada a la Presidencia de la Nación, impulsó el fortalecimiento de este espacio en múltiples perspectivas, desde su crecimiento burocrático, la formación de sus agentes, el desarrollo de normativas, procedimientos, y el crecimiento exponencial del alcance de su acción que atañía ahora a sectores sociales que anteriormente habían sido desatendidos.

En la provincia de Santa Fe la aplicación del artículo 12 del Decreto-ley 15704, que había convertido en delegaciones regionales de la STyP a las reparticiones locales relativas a la regulación laboral, implicó la modificación del organigrama existente en el ministerio de Salud y Trabajo, sobre todo a partir de la gestión del interventor Oscar Aldrey entre finales de 1944 y 1946, que operó un importante fortalecimiento de la rama de sanidad y acción social del MSPyT, liderado por Carlos Lambruschini y Lorenzo García;20 mientras que la sección relativa a Trabajo conservó solo un

\footnotetext{
19 María Paula Luciani, «La etapa formativa de la Secretaría de Trabajo y Previsión (1943-1946): primeros pasos organizativos y figuras relevantes», en Anuario del Instituto de Historia Argentina, $\mathrm{N}^{\circ}$ 14, 2014. Recuperado a partir de: http://www.anuarioiha.fahce.unlp.edu.ar/article/view/IHAn14a01. ${ }_{20}$ Lorenzo García tendría una importante actuación hasta 1950 en el ministerio provincial. Desde dicho año pasaría a incorporarse como Subsecretario Técnico del Ministerio de Salud Pública de la Nación. Al respecto, Natalia Bacolla, «Nuevas capacidades estatales para una sociedad transformada.
} 
instituto específico - concerniente a la investigación, fomento agrícola y algunas incumbencias menores de inspección-. Como señalaba un agudo análisis del laboralista Mariano Tissembaum, en el primer número de La Gaceta del Trabajopublicación que se constituiría en un observatorio privilegiado de las novedades jurídicas y regulatorias sobre el campo desde 1945-, estas modificaciones planteaban una situación compleja. Por una parte, implicaron un desplazamiento jurisdiccional - que además dividía en dos delegaciones regionales a la provincia, una con sede en Santa Fe y otra en Rosario-. Pero por otra, si bien modificaba la organización institucional no sucedía lo mismo en cuanto a las normas de actuación, planteándose la paradójica situación de constituirse en un ente de jurisdicción nacional que aplicaba una legislación de carácter provincial. ${ }^{21}$ A esta hibridez jurídica debe añadirse, al igual que en otros espacios provinciales, los roles políticos que asumirían las delegaciones regionales de la $\mathrm{STyP}$-sumado a las filiales de la Confederación General del Trabajo (CGT) - en la conformación del nuevo movimiento. En la provincia de Santa Fe la conflictividad que caracterizó dicho proceso en el ámbito nacional se agravaría localmente con el suicidio del gobernador electo; que llevaría, como solución de compromiso, a la designación de un nuevo candidato, Waldino Suárez - filiado al laborismo y fuertemente vinculado al catolicismo local-.Sus intentos de retener la capacidad de regulación del ámbito laboral en la esfera de la agencia provincial - propuestos en un plan Trienal- fracasaron frente al fortalecimiento a escala federal de las delegaciones del ahora Ministerio de Trabajo y Previsión Social (MTyP). La gestión de Suárez tuvo como desenlace su clausura anticipada, a consecuencia de una intervención federal al Ejecutivo provincial a inicios de 1949.

Ahora bien, si para los años cuarenta el Estado provincial reconocía una considerable pericia en la resolución administrativa de la conflictividad laboral; estas capacidades no fueron acompañadas por la constitución de una magistratura específica del trabajo. Varios proyectos se presentaron entre 1934 y 1942, naufragando a pesar de la buena recepción tanto en el ámbito legislativo, como en el foro provincial, federaciones gremiales del comercio y la industria, como así también

Instituciones y políticas sanitarias en la provincia de Santa Fe, primera mitad del siglo xx», en Trabajos y comunicaciones, $\mathrm{N}^{\circ}$ 44, UNLP, 2016.

${ }^{21}$ Mariano Tissembaum, «La legislación del trabajo y la cuestión jurisdiccional», en Gaceta del Trabajo, N ${ }^{\circ}$ 1, abril-junio de 1945, Buenos Aires, Editorial Bibliográfica Argentina. 
de trabajadores. La experiencia provincial no fue una excepción respecto a las dinámicas nacionales en la institucionalización de la magistratura del trabajo, conformándose en paralelo al peronismo. Movimiento que constituía su lenguaje e identidad en torno a muchos de los conceptos que largamente habían sedimentado, desde diversas tradiciones y en el «nuevo derecho», y que se resumían en la idea de «justicia social». Dando lugar, a pesar de un consenso largamente elaborado y receptivo a los debates internacionales, a una disputa en múltiples planos surcada por una confrontación de clave ideológica. ${ }^{22}$ Estas tensiones, como hemos demostrado en otros trabajos, se expresarían en el carácter complejo y heterogéneo que asumió el proceso de conformación del fuero laboral en las provincias, y el fracaso de las acciones del Poder Ejecutivo nacional para constituirlo en una rama de la justicia federal -aspiración contenida ya en el decreto-Ley 32347 de noviembre de 1944, convertido en ley 12.948 en febrero de 1947-.23

Luego de un largo año de disputas, y con la fuerte intervención de las delegaciones del MTyP y la CGT local, el 29 de enero de 1949 recibirían sanción legislativa los proyectos de leyes de creación del fuero laboral provincial. Promulgadas el 3 de febrero de ese mismo año, una ley creaba los tribunales del trabajo, la 3481, y la otra, la 3480, establecía su código procesal. Esta última de breve vida ya que sería derogada antes de ser aplicada, en octubre de 1949, por la nueva Ley Orgánica de Tribunales, $\mathrm{n}^{\circ} 3611$, que se adecuaba a la recientemente reformada constitución provincial. ¿Cómo se definiría finalmente la arquitectura del fuero laboral santafesino? Ésta optaba por la composición exclusivamente letrada - sin representantes corporativos como sucedía en otros casos nacionales ${ }^{24}-$ y a diferencia de otras provincias que se habían inclinado por la oralidad y los tribunales colegiados, sostenía como los estrados laborales federales la doble instancia y el procedimiento escrito. El despliegue territorial no era complejo: dentro de la primera circunscripción, una Sala de apelaciones y dos jueces del trabajo con sede en Santa Fe; y en la segunda circunscripción, con asiento en Rosario, una Sala de apelaciones y tres jueces del trabajo. Creaba a su vez en el territorio provincial tres jueces seccionales del trabajo: uno en el sur con sede en San Urbano (Melincué), otro en el

22 Palacio, La Justicia, 2018.

23 Bacolla, «El lugar...», 2018.

24 Sobre la estructuración del fuero laboral en otros casos nacionales: Alain Chatriot, Odile JoinLambert y Vincent Viet, Les politiques du Travail (1906-2006): acteurs, institutions, réseaux, Rennes, Presses Universitaires de Rennes, 2006 y Fink y Palacio, 2018. 
centro, en Rafaela, y otro en el norte, con asiento en Jobson (Vera); e incorporaba los jueces de paz letrados de las cabeceras de departamentos y distritos, que entendían en contenciosos de hasta mil pesos. Entre los puntos que se veían con positividad tanto en la opinión pública como entre los expertos, se rescataba que, a diferencia de otras provincias, el código no contemplaba una instancia de conciliación previa al inicio de la acción, sino que habilitaba al juez a establecerla en cualquier momento del proceso. La misma opinión se vertía sobre los mecanismos de nombramiento de oficio de los peritos; y la decisión del legislador de autorizar a fallar ultra petita, es decir sobre aspectos no referidos en la demanda inicial, y permitir litigar a las partes con carta de pobreza. Pero, sin embargo, varios aspectos fueron objeto de crítica. Las falencias advertidas se concentraban en cinco aspectos ya sindicados en el debate previo. En primer lugar, se insistía en la necesidad de aumentar el número de juzgados creados, que se consideraban por demás exiguos para hacer accesible los estrados a los trabajadores rurales y de las pequeñas poblaciones de la provincia. En segundo lugar, se subrayaba la «mala técnica» del aspecto procedimental. ${ }^{25}$ En tercer lugar, la ausencia de un ministerio público del trabajo - que hacía recaer en consecuencia la tarea en los fiscales de la justicia ordinaria y en los defensores de pobres e incapaces - era vista como otra traba importante para lograr la rapidez que este tipo de trámite judicial prometía. Lo mismo ocurría con la opción por la doble instancia y el procedimiento escrito. En cuarto lugar, se señalaba la inequidad de las disposiciones que asignaban a la provincia el pago de los peritos en caso de insolvencia del trabajador solamente, sin adoptar el mismo principio para el empleador. ${ }^{26}$ Por último, un nudo importante de las críticas se dirigía a la definición de competencia, la cual se recortaba sobre «las causas que se susciten entre empleadores y trabajadores por conflictos individuales de derecho fundadas en las

\footnotetext{
25 Héctor Genoud, «La competencia de los tribunales del trabajo en la legislación provincial», en Gaceta del Trabajo, $\mathrm{N}^{\circ}$ 9, abril-junio de 1949, Buenos Aires, Editorial Bibliográfica Argentina, 4. Las críticas sobre la «mala técnica» de la ley se concentraban en cuatro aspectos: primero, la indefinición sobre las situaciones de recusación y excusaciones, actuaciones judiciales y notificaciones; segundo, que el código no adopta la representación letrada obligatoria para estos actos; tercero, en cuanto a las disposiciones que garantizaban la celeridad del proceso, se consideraba que al no ser los tribunales orales y colegiados dilataba el proceso, conjuntamente con algunos artículos procedimentales; finalmente, respecto al ofrecimiento de la prueba consideraban que era desfavorable para el actor ya que debía ofrecer al demandado todos los elementos, mermando así los beneficios de la «inversión de la prueba».

${ }^{26}$ Alfredo Ruprecht, «El fuero del trabajo en la provincia de Santa Fe», en Gaceta del Trabajo, $\mathrm{N}^{\circ} 8$, enero-marzo de 1949, Buenos Aires, Editorial Bibliográfica Argentina, 212. Respecto a las opiniones circulantes en algunos periódicos locales durante el tratamiento de la ley: El Litoral, Santa Fe, 31/o8/1948, El Orden, Santa Fe, 3/o9/1948 y La Capital, Rosario, 4/02/1949.
} 
disposiciones de los contratos de trabajo, empleo, aprendizaje o de ajustes de servicios», y todos aquellos contenciosos derivados de disposiciones legales del derecho laboral. Esta prescripción de la ley circunscribía los estrados del trabajo al litigio individual, y excluía los diferendos por previsión social, concentrándose solo en las relaciones laborales y dejando de lado aspectos de un más amplio «derecho social».

\section{Usos de la justicia laboral en las sentencias del Tribunal $n .^{\circ} 1$ de Rosario: a propósito de los convenios colectivos, o «contratos con alma de ley» ${ }^{27}$}

El Juzgado $\mathrm{n}^{\circ} 1$ de Rosario fue de los primeros en ponerse en funcionamiento, hacia diciembre de 1949, aun cuando en el resto de la provincia el nuevo fuero se iría constituyendo lentamente a lo largo del siguiente año. A la escasez de recursos e infraestructura edilicia se agregaban las dificultades para reclutar un funcionariado judicial especializado, ya que, si bien la universidad local contaba con un instituto dedicado al laboralismo, el derecho del trabajo no constituía una especialidad generalizada en la enseñanza jurídica, a lo cual se sumaba la consideración de este fuero dentro del Poder Judicial como de rango menor a otros como los civiles, comerciales o penales.

Su actividad concentró una buena intensidad en sus primeros dos años de funcionamiento, estabilizándose en el resto del período hasta la revolución de 1955, que daría fin al gobierno peronista. ${ }^{28}$ Varios factores pueden explicar estas variaciones. Por una parte, la expectativa que la creación del nuevo fuero parece haber originado en sus inicios, como indica la gran cantidad de casos que entre finales de 1949 y mediados de 1950 se enviaron a las cámaras del trabajo en la provincia para apelar las sentencias y radicaciones en otras ramas del Poder

\footnotetext{
${ }^{27}$ La frase encabeza las fundamentaciones de la presentación del proyecto de ley sobre convenios colectivos y comisiones paritarias al Congreso Nacional en 1953. Cf. Diario de Sesiones de la Cámara de Diputados de la Nación, Año Legislativo 1953, Reunión 38², 1750-1817.

${ }_{28} \mathrm{El}$ número de causas sobre las que se dictan sentencias son las siguientes: 247 para 1950, 330 para 1951, 299 para 1952, 288 para 1953, 225 para 1954, 245 para 1955, 179 para 1956. Fuente: Índice libros de sentencias del Juzgado de $1^{\text {a }}$ nominación, segunda circunscripción, Rosario (1949-1957). Los otros dos tribunales laborales presentan similares tendencias en su actividad. Archivo del Poder Judicial de la Provincia de Santa Fe, Segunda Circunscripción (APJPSF).
} 
Judicial.29 Un segundo hecho estructural de incidencia en estas oscilaciones puede ser atribuido a una cierta descompresión en la proporción de casos recibidos por cada nominación, producida por la ampliación del número de juzgados luego de la ley modificatoria de finales de 1951. Por último, el propio contexto económico y político entre los años 1952 y 1953 se constituye en un dato no menor, atendiendo a los llamamientos que desde el gobierno se hacía a la moderación de los reclamos sindicales, en el contexto del llamado «plan de estabilización».

Pero ¿qué motivos impulsaban a los trabajadores y patronos a litigar individualmente, habida cuenta que, como hemos señalado en el apartado anterior, durante esos años se habían consolidado paralelamente un conjunto de herramientas de regulación de las relaciones de trabajo en términos colectivos, a través de las agencias del MTyP? Las sentencias muestran una articulación de hecho con las delegaciones regionales de dicha instancia administrativa, cuyos expedientes-en general invocados en los pleitos judicializados- exponen su rol tácito como primera exhortación conciliatoria, mecanismo ausente en el procedimiento de la justicia laboral provincial. En cuanto a las causales más asiduas de las demandas aquella que prevalece es la que se caratula como «cobro de pesos».30 Estas presentan en orden de importancia demandas por errores o ajustes en las indemnizaciones por despidos, por rectificación del monto acordado en la instancia administrativa, la deuda de salarios -en su mayor parte por enfermedad, feriados o ausencia justificada pero no reconocida por la patronal, etc.-, y la aplicación de la nueva legislación social -sobre vacaciones, sueldo anual complementario, jubilación-. Un punto particularmente repetido en la conflictividad expresada por estas causas se vinculaba con la aplicación de convenios colectivos; en tanto estos en general definían la regulación de los salarios, los mecanismos de control de la disciplina interna de las fábricas, las situaciones aceptadas por patronales y sindicatos respecto a suspensiones o despidos y la actuación de las comisiones paritarias.

\footnotetext{
29 APJPSF, Cámara de Apelaciones del Trabajo, Segunda Circunscripción, Libro de resoluciones, Tomo I 1949-1951. Varias disposiciones establecieron el modo en que debían ir definiéndose la competencia y la distribución de casos ya presentados durante el año 1949 en las instancias civiles y comerciales, como así también las correccionales, sobre todo en lo relativo a la ejecución de sanciones emanadas de las delegaciones regionales.

$3^{\circ}$ En el tribunal en estudio, para los años cincuenta sobre 330 sentencias, 219 llevan esta carátula; en el año 1953, 255 sobre 288 sentencias; 153 sobre 179 para el año 1956. Fuente: APJPSF, Libros de sentencias, Juzgado de $1^{\text {a }}$ nominación, Segunda circunscripción, Rosario (1949-1957)
} 
Como se ha advertido para el caso nacional, la recurrencia de este tipo de litigios respondía a un conjunto de condiciones presentes en los modos que había adquirido la regulación de las relaciones en el mundo del trabajo durante la cristalización del peronismo.31 Por una parte, el problema jurisdiccional que había creado la conversión de las agencias locales en delegaciones de la Secretaría de Trabajo y Previsión, asumiendo las tareas de aquellas en cuanto a las resoluciones y mediaciones en conflictos colectivos de trabajo en las provincias. Por otra parte, en 1944, el Decreto 21877 respaldaría ese cambio fortaleciendo el rol del Poder Ejecutivo nacional, al determinar el carácter obligatorio de las convenciones colectivas como así también su tramitación ante un representante de la, entonces, STyP. En 1945, este instrumento sería reforzado con un nuevo decreto, el 23852 sobre asociaciones profesionales, el cual determinaba las diversas categorías de las corporaciones, desde aquellas solo con personería a las que anudaban la representación gremial, siendo estas últimas las que concentrarían las capacidades de negociación, representación e interlocución con el Estado. Estas herramientas institucionales a la par que reglaban las relaciones capital-trabajo, constituían medios de disciplinamiento obrero y patronal. En el organigrama del MTyP, el control de estos aspectos recayó en la Dirección General de Trabajo y Acción Social Directa, a cargo de una figura fuerte del peronismo por sus vínculos políticos y gremiales: Hugo Mercante. Junto a esta Dirección, la Inspección de Delegaciones Regionales cumpliría un rol clave en el proceso de homogenización, ya que sus funcionarios asesoraban en la mediación y resolución de los conflictos locales a la par que difundían las directivas técnicoadministrativas para coordinar el trabajo a nivel provincial con las autoridades nacionales. Estos delegados regionales a su vez tenían en muchos casos fuerte inserción en el sindicalismo local. Un ejemplo de ello puede encontrarse en la carrera de uno de los delegados de la regional Rosario, Alejandro Giavarini-líder del gremio

\footnotetext{
${ }^{31}$ Sobre lo que sigue remitimos a los trabajos de Ricardo Gaudio y Jorge Pilone ya citados en nota 5; también Luise Doyon, Perón y los trabajadores. Los orígenes del sindicalismo peronista, 1943-1955, Buenos Aires, Siglo Veintiuno Editores, 2006 y el clásico estudio de Hugo del Campo, Sindicalismo y peronismo. Los comienzos de un vínculo perdurable. Buenos Aires, Clacso, 1983, como así también el de Juan Carlos Torre, La vieja guardia sindical y Perón. Sobre los orígenes del peronismo, Buenos Aires, Sudamericana, 1990, Palacio, Juan Manuel, La justicia, 2018 y María Paula Luciani, De la Secretaría al Ministerio de Trabajo y Previsión: transformación estatal, elencos y frentes de intervención durante el primer peronismo, Unsam/Idaes, Tesis de doctorado, 2016.
} 
ferroviario en los talleres ubicados en la cercana ciudad de Pérez- y que llegaría a ser ministro de la cartera nacional en $1953.3^{2}$

En este sentido, la opción del Poder Ejecutivo nacional por la resolución pragmática de las demandas gremiales -otorgando mejoras negociadas colectivamente y acordes con la relación de fuerza prevaleciente en cada sectorantes que una justicia laboral federal y la sistematización y ordenamiento en un código común, profundizó la hibridez del sistema. Por una parte, tribunales provinciales que aplicaban leyes nacionales y viceversa, agencias estatales federales que supervisaban el cumplimiento de la legislación provincial. Pero, por otra, abría un terreno nebuloso en la articulación entre el Poder Judicial y el administrador, ya que si bien este último era el encargado de reglar los protocolos de negociación colectiva, conciliación y arbitraje, quedaba abierta la vía judicial para impugnarla. La ausencia de una ley sobre convenios colectivos y su régimen de aplicación, recién sancionada en 1953, dejaba abierto un campo de disputas sobre diversos aspectos jurisdicciones de aplicación, cualidades jurídicas de los actores, reparticiones ejecutoras, capacidades de las comisiones paritarias, entre otros- que darían espacio a resistencias y cuestionamientos. Una buena parte de estas estrategias de impugnación tendrían su escenario en los tribunales del trabajo.

Según surge de las sentencias analizadas, el malestar no derivaba solo del corrimiento de las rutinas de negociación colectiva del ámbito local al nacional, sino que a su vez expresaba el descontento frente a los cambios que había suscitado el fortalecimiento de nuevas direcciones gremiales.33 En este sentido, los estrados replicaban en términos individuales disputas corporativas que también se dirimían en el ámbito político. Como ha demostrado Silvia Simonassi las cámaras empresarias rosarinas denunciaron activamente las condiciones en las que se firmaban los convenios colectivos, considerando un trato discriminatorio para las industrias del interior el recurso a una representación mediada por cámaras de la Capital Federal y

\footnotetext{
${ }^{32}$ Sobre estos aspectos remitimos a Luciani, 2016.

$33 \mathrm{Al}$ respecto Silvia Simonassi ha analizado los casos particulares de las industrias metalúrgicas y de la industria del calzado en la ciudad de Rosario: «Empresarios, conflictividad obrera y negociación colectiva durante el primer peronismo en la ciudad de Rosario", en Nuevo Mundo. Mundos Nuevos, [en línea] Questions du temps présent, puesto en línea 07/2016, última visita: 04/2017. Recuperado a partir de: http://nuevomundo.revues.org/69461. También: Mercedes Prol, «El Partido Peronista en Santa Fe y el movimiento obrero. Relaciones de poder, acuerdos y conflictos, 1946-1955», en Historia Regional, Sección Historia, ISP, $\mathrm{N}^{\mathrm{O}}$ 3, año XXVI, No 31, 2013, 9-26.
} 
que soslayaba las diferencias entre las diversas condiciones regionales de trabajo existentes en el país. Por otro lado, los sindicatos obreros que habían liderado algunos de los sectores económicos más activos de la ciudad-el metalúrgico, la industria del calzado o la frigorífica - denunciaban su desplazamiento de las firmas de convenios a favor de gremios pro-gubernamentales.

En este registro los argumentos de impugnación de las regulaciones surgidas de estos actos por parte de las patronales se repiten en las sentencias. Por una parte, objetando la obligatoriedad local de convenios que no habían sido firmados dentro de la esfera de acción de la Regional rosarina del Ministerio de Trabajo -réplica que a veces se extendía al desconocimiento de estatutos profesionales específicos $34-$ y aduciendo la preexistencia de acuerdos locales o bien la inconstitucionalidad de disposiciones emergentes de negociaciones de las cuales no habían participado bajo ninguna representación, ni suscripto a posteriori.35Por otra parte, invocaban la ausencia de conflictos en sus establecimientos y por ende la improcedencia de la aplicación de un convenio, que consideraban necesariamente debería haber sido ocasionado por un pliego de demandas de sus trabajadores o la huelga. Como en el caso de la Cooperativa de Tamberos de la zona de Rosario, frente a la demanda de su exempleada Andrea Urquija, a la cual contestaba sosteniendo que no era procedente que

...deba cumplir las disposiciones del convenio colectivo porque no ha tenido conflicto con su personal, y en consecuencia no ha estado sometida a jurisdicción de funcionario alguno, que no puede prevalecer contra un tercero los acuerdos o laudos en los que no ha sido parte; que el Director de Trabajo y Acción Directa del Ministerio de Trabajo y Previsión carece de jurisdicción y competencia para actuar en la provincia. ${ }^{36}$

El rechazo de la argumentación por parte del juez en esta causa fue taxativo, como en otros fallos. Tal la demanda presentada por un oficial tornero, Néstor

34 En las sentencias analizadas los estatutos y convenios más frecuentemente discutidos corresponden a las siguientes ramas de actividades laborales: el llamado Laudo Mercante, para los metalúrgicos, el que regula a la industria del calzado y vestido, el periodismo, los trabajadores gráficos, del comercio, la marina mercante, el estibaje, gastronómicos, diversas especialidades de la construcción y el estatuto del peón.

35 Un buen panorama de conjunto puede encontrarse en la descripción de un miembro de la Federación Gremial: Eduardo Astesano, «Convenios colectivos. Estudio de los convenios inscriptos en la Delegación Regional Rosario», en Revista de la Federación Gremial del Comercio y la Industria, N ${ }^{\circ}$ 225, 06/1946, 235-242.

${ }_{36}^{6}$ Sentencia $\mathrm{N}^{\circ} 49$, Urquija contra Cooperativa Tambera Rosario, Juzgado de Primera Nominación, Segunda circunscripción, APJPSF, Libro de sentencias, Tomo I, 1949-1951, 31/o5/1950, folio 84. 
Violetta, contra la razón social Núñez Hnos, de actividades metalmecánicas. Este trabajador alegaba haber sido despedido junto a otros compañeros por solicitar una mejora en su sueldo, y que siendo reincorporado con la intervención del Sindicato de Obreros de la Industria Metalúrgica (SOIM) y un funcionario del Ministerio de Trabajo la delegación Rosario se hizo un acuerdo con la patronal por la cual se dejaban sin efecto los despidos y se concedía un aumento de sueldo, el cual sin embargo no contemplaba las condiciones del Laudo Mercante. Por lo tanto, reclamaba la diferencia de salarios. Entre los argumentos esgrimidos por la patronal se sostenía que

El convenio colectivo de los metalúrgicos no se aplica a su actividad, ni el suscripto por el sindicato del automóvil y anexos, pues no ha intervenido en su tratativa ni lo ha suscripto. El 30 de julio por libre y espontánea voluntad del personal y de la empresa se suscribió con presencia de un inspector del Ministerio de Trabajo, delegación Rosario, un convenio por el cual se otorgan mejoras al personal, expirando el mismo el 31 de diciembre de 1949, lo cual hace inaplicable cualquier otro convenio ya que el celebrado con el personal lo fue hecho ante la autoridad de aplicación. 37

En esta ocasión el juez Alfredo Ruprecht reiteraba su decisión de no dar lugar a la argumentación empresaria, en tanto que:

El convenio colectivo no se rige, evidentemente, por las normas civiles de derecho privado, no establece un vínculo entre partes determinadas, sino solamente cláusulas para los futuros contratos individuales del trabajo. El principio de la libertad de contratación ha quedado limitado por razones de bienestar social, cuya concretización en último análisis, es una rama de orden público. En realidad, puede decirse que, los convenios colectivos en muchos aspectos se asemejan a los estatutos profesionales. [...] Suponer que los convenios locales, parciales, puedan tener primacía sobre uno general, total, es ir contra los principios fundamentales y la naturaleza jurídica propia de esta institución. 38

La sentencia de Ruprecht sobre el litigio sostenido por Violetta contra el taller Núñez Hnos. sentaba así jurisprudencia-invocada en pronunciamientos judiciales posteriores- e incidiría sobre la aplicación de los convenios colectivos, coadyuvando en sentido positivo en la pugna de los trabajadores por la ampliación de derechos. El

37 Sentencia $\mathrm{N}^{\circ}$ 113, Violetta contra Núñez Hnos. y Cía., Juzgado de Primera Nominación, Segunda circunscripción, APJPSF, Libro de sentencias, Tomo I, 1949-1951, 23/o8/1950, folio 188.

${ }_{38}^{8}$ Sentencia $N^{\circ} 113$, Violetta contra Núñez Hnos. y Cía., Juzgado de Primera Nominación, Segunda circunscripción, APJPSF, Libro de sentencias, Tomo I, 1949-1951, 23/o8/1950, folio 189. 
estrado fue, en este sentido, una caja de reverberación de conflictividades que se habían expresado también en términos corporativos en la delegación regional de la STyP, entre la Cámara de Industriales Metalúrgicos (CIM) y la oficialista Unión de Obreros Metalúrgicos (UOM) - a la cual secundaría en este conflicto la dirigencia gremial desplazada del soIM, de filiación comunista-. El principal punto de discrepancia-que además de desarrollarse en sede administrativa se prolongaría en huelgas y lockouts a lo largo de 1948- se concentró en la definición de la jurisdicción en la que debía realizarse la negociación colectiva. Si bien la resolución de esta larga conflagración dejó clara la respuesta, ratificando la jurisdicción nacional, los industriales rosarinos del sector, particularmente los propietarios de talleres de menor escala, como el caso en análisis, persistieron en su resistencia: bien insistiendo en el desconocimiento de jurisdicción o pugnando por quitas zonales,que llegaron a mermar salarios locales hasta en un 10 \% respecto de los convenios suscriptos para Capital Federal.39

Junto a la naturaleza social del «nuevo derecho», como así también la supremacía de las convenciones nacionales y por rama, sobre las locales y por industrias, los fallos recalcan que estas prácticas de negociaciones además implican un paso previo de regulación estatal que radicaba en «... la existencia de colectividades - sindicatos - al menos del lado obrero, oficialmente reconocidas y nacidas de la convención celebrada entre el patrón o la asociación patronal por un lado y estos sindicatos con personería legal perfectamente deslindada...».40 Y por tanto, continuaba el magistrado, aceptar acuerdos sin su intervención implicaría que «...todo convenio sería una declaración lírica, ya que bastaría la voluntad de

\footnotetext{
39 Otro ejemplo interesante y que delinea los estrados, a pesar de procesar demandas individuales, como escenario de disputas colectivas es el de algunos casos de obreros metalúrgicos que litigan por diferencias en el cobro de indemnizaciones. Particularmente estos casos se concentran en el año 1950 en varios talleres de la ciudad y alrededores - por ejemplo, Preumayr Cía. RL, Talleres Eureka, Benzi \& Cia SRL, EMAT SRL-, que aducen que los despidos y suspensiones son provocados por la escasez de materias primas o sus cupos regulados. Gran parte de estos casos son perdidos por las patronales, que a ojos del juez y los peritos contables no logran demostrar la situación. La coyuntura que acompañan estos juicios puede darnos otra lectura: constituye un momento álgido de movilizaciones y huelgas que terminarán con la firma de un nuevo convenio colectivo para la rama metalúrgica en marzo de 1949. La contracción económica de estos años implicó efectivamente un momento de escasez de materias primas y de resistencias de los sectores empresarios a aplicar las subas salariales del nuevo convenio que rondaban el 30\%. Un análisis detallado de estas confrontaciones puede encontrarse en el trabajo ya mencionado de Silvia Simonassi. Sobre los convenios mencionados y las posiciones de los gremios: Cámara de Industriales Metalúrgicos de Rosario - Actas Asambleas Generales: 18/3/49; 28/6/49 por ejemplo. También de la misma cámara, Actas Comisión Directiva, 5/8/49.

40 Sentencia $N^{\circ} 113$, Violetta contra Núñez Hnos. y Cía., Juzgado de Primera Nominación, Segunda circunscripción, APJPSF, Libro de sentencias, Tomo I, 1949-1951, 23/o8/1950, folio 189.
} 
cualquier grupo de trabajadores de un establecimiento determinado para dejarlo sin efecto. Los patrones deben ajustar todos sus contratos a las cláusulas del convenio colectivo vigente». 41

Otro punto complejo que emerge en estos diferendos es el de la composición y funciones de las comisiones paritarias, cuyas actuaciones habían sido no pocas veces impugnadas.42Un ejemplo interesante de los modos en que estas conflictividades colectivas se tramitaban en los estrados puede ilustrarse a través del litigio seguido por dos trabajadores gráficos contra el periódico Tribuna de la ciudad de Rosario. Miguel J. López del Cerro y Vicente Rolando Demarco presentaban su demanda por despido y salarios adeudados luego de haber sufrido una suspensión de más de tres meses a inicios de 1949. La defensa de los trabajadores gráficos sostenía que la Comisión Paritaria instituida por el estatuto del periodista - Ley 12. 908- ya había revocado la suspensión de tareas, constatando que no había mediado ningún conflicto específico con estos empleados o falta de trabajo. Por su parte Demarco agregaba otro elemento a la contienda judicial reclamando «... diferencia de salarios, pues pese a un contrato nulo celebrado a instancias de la patronal, en que figura como colaborador permanente, siempre se ha desempeñado como retocador y letrista». Señalaba en ese sentido las recurrentes «maniobras de la patronal», tanto en 1944 cuando se sanciona el Decreto 7618-que regula al gremio de los trabajadores gráficos- como ante la sanción posterior del estatuto del periodista-Ley 12.908-; haciéndole firmar en ambas ocasiones contrato con un salario menor a lo estipulado en los mencionados convenios. La patronal sostuvo su rechazo a esta imputación e impugnó la actuación de la mencionada comisión paritaria por considerarla sesgada en su composición:

[La patronal] niega que no haya querido abonar los salarios reclamados, sino que por causas ajenas a su voluntad y por el hecho de terceros se vio obligada a interrumpir su aparición, suspendiendo a los actores y demás empleados, primero por quince días y luego por nueve más. El personal suspendido planteó el recurso a la comisión paritaria establecida por la ley 12908, la cual revocó la resolución antedicha. Esta decisión fue violatoria de la libertad de empresa, pues la citada comisión solo puede intervenir en

\section{${ }_{41}^{1}$ Ídem.}

42 Sentencia $N^{\circ}$ 157, Miguel J. López del Cerro y Vicente Rolando Demarco contra Diario Tribuna S.A. Libro de sentencias, Tomo I, 1949-1951, 13/10/1950, folios 263 a 272 (APJPSF).Un caso similar en: Sentencia $\mathrm{N}^{\circ} 158$, Hugo José Pinto contra Diario Tribuna S.A, APJPSF, Libro de sentencias, Tomo I, 1949-1951, 13/10/1950, folios 273 y 274. 
suspensiones disciplinarias; además no se cumplieron las disposiciones legales establecidas en la resolución 2178/45, pues no se notificó a los representantes patronales de la fecha y cuestiones a tratarse; se resuelve la cuestión por el voto de dos representantes obreros y uno patronal...».43

Las argumentaciones de la defensa patronal en su descargo sobre la acusación de eludir las obligaciones emergentes de los convenios colectivos vigentes fueron refutadas por las testimoniales ofrecidas, no solo por los compañeros y jefes del taller donde se desempeñaban los demandantes, sino además por el codirector del periódico y el protesorero. El veredicto del juez ratificóla validez de la composición y decisiones de la comisión paritaria, y la consistencia en definitiva de lo demandado, enfatizando los argumentos jurídicos que sostenían la «desigualdad igualadora» del derecho laboral. Pero el contencioso corporizado en las demandas de López del Cerro y Demarco puede insertarse en una atmósfera de malestar que desbordaba los diferendos individuales, y que remitían a un escenario de tensión entre la Federación Gráfica Rosarina (FGR) - de alineamiento peronista- y propietarios de diarios opositores como Tribuna, Crónica y La Acción en la negociación de un pliego de condiciones luego de medidas de fuerza que darían lugar a un nuevo convenio.44 Las acciones judiciales de este modo operarían - aunque en un registro diferente a las agencias administrativas-,no solo sobre las resistencias que suscitaban las nuevas regulaciones sobre el mundo del trabajo sino además, en la construcción discursiva de los clivajes de clase y sus identificaciones políticas en el campo de la querella entre peronismo y antiperonismo.

Otro cariz de las disputas por el control de las condiciones y regulación del contrato laboral que es puesto de relieve en las sentencias analizadas es aquel de la inclusión de los trabajadores temporarios - jornaleros u obreros a destajo- en las regulaciones de la legislación laboral y los convenios específicos principalmente en torno a las actividades con flujos estacionales como las gastronómicas, rurales, de la

43 Sentencia No 157, 13/10/1950 Miguel J. López del Cerro y Vicente Rolando Demarco contra Diario Tribuna S.A., folio 263.

44 El Litoral, Santa Fe, 21 de enero de 1949, 3 «Solicitada de los directores de los diarios La Acción, Crónica y Tribuna de Rosario» y La Capital, Rosario, 20 de enero de 1949, 5 «Solicitada de la Federación Gráfica Rosarina». A inicios de ese año 1949, en el que tenían lugar los hechos que originarían la causa, varios trabajadores gráficos se habían negado a componer una solicitada primero y editoriales después que consideraban iban en contra del gremio que los representaba. La resistencia generó el despido o suspensión de los trabajadores comprometidos -alegando que su acción había impedido la normal circulación de los periódicos- y dio origen a un conjunto de presentaciones ante la delegación del Ministerio de Trabajo. 
construcción; o en rubros donde la provisión de trabajadores eventuales era regulada por las estructuras sindicales, como la actividad portuaria. En su mayoría las resoluciones judiciales tienden a extender la protección legal a estas categorías laborales, y a constituirlos discursivamente dentro del colectivo de «trabajadores». Es el caso del fallo recogido en la sentencia que zanja la demanda por despido interpuesta por Isaías Garay, un estibador que había trabajado en la empresa cerealera Northern Elevator Co. Ltd. desde 1935 y fuera despedido de manera «verbal», según su testimonio, el 22 de agosto de 1949. El fundamento de rechazo de la defensa patronal giraba en torno a la demostración del carácter eventual del trabajador «sin efectividad ni permanencia por ser jornalero», «no trabajador regular», y por ende no alcanzado por las regulaciones de las leyes laborales y el convenio colectivo de la rama.45Sostenida en las testimoniales recabadas, los peritajes contables y el informe sindical la resolución favorable del juez concluía «que la forma de retribución no es índice exclusivo del carácter del empleo»; sino que su permanencia al servicio de la acopiadora por más de una década y media enunciaba la perdurabilidad del lazo laboral.

Por otra parte, un buen número de sentencias son atravesadas, más allá del pleito específico que invocaban, por el disenso entre patronos y trabajadores en torno a los criterios para determinar qué convenios colectivos alcanzaban a las diversas actividades laborales. Si en parte algunos casos muestran los diversos poderes de negociación de sindicatos de una misma rama de industria, por otra ponen de relieve las tensiones con prácticas de negociación previas, que localmente habían habilitado concertaciones de un mismo gremio con varios sectores patronales afines a la rama de actividad. Es el caso de la industria de la construcción, como puede verse por ejemplo en la demanda interpuesta por los oficiales albañiles cavadores Francisco Fanoy y Juan Antonio García, quienes alegaban haber sido despedidos injustificadamente luego de finalizar la obra de pavimentación que la empresa porteña Sucesores de José Figuerola tenía a cargo en la ciudad de Rosario. Entre los argumentos los obreros señalaban que no se había cumplido con lo estatuido en el convenio en el cual se consideraban incluidos -el de cavadores de sótanos, corralones y compraventa de materiales de construcción- puesto que no se les había pagado los

45 Sentencia $\mathrm{N}^{\mathrm{o}} 1$ (1950), 2/02/1950, Isaias Garay contra Northern Elevator Co Ltd. Estibador, APJPSF, Libro de sentencias, Tomo I, 1949-1951, 02/02/1950, folios 1 a 4. 
aumentos de salarios estipulados y tampoco contemplado los procedimientos para dar por terminado el contrato laboral ante falta de trabajo, que debía comenzar por los empleados de menor antigüedad. Gran parte de esta disputa por despido se concentraba no tanto en corroborar si había habido ruptura justificada del contrato de trabajo, sino en definir qué convenio debía ser aplicado a esta categoría: si la reclamada por los albañiles -y respaldada por su sindicato- o bien la de empedradores, según la argumentación de la patronal. 46

Estos ejemplos, surgidos de la indefinición jurídica en que quedaron los convenios colectivos hasta la sanción de la Ley 14520, delinean en su conjunto diversas vías a través de las cuales los estrados se fueron afirmando como escenarios de aprendizajes sociales de las nuevas dinámicas que adquirirían las relaciones en el mundo del trabajo, a la par que de constitución práctica de la regulación del conflicto. Así, por una parte la naturaleza jurídica particular del convenio colectivo -que se escapaba de las características del contrato de derecho civil, a la vez que desbordaba lo individual- generaba en muchas de las causas una situación original: aunque la sentencia refería a un caso particular, sentaba jurisprudencia sobre derechos colectivos. Además, la obligatoriedad a todos los empleadores de la rama respecto de convenios de alcance nacional abonaba una considerable, aunque no completa, homogenización de las condiciones de contratación de la mano de obra para actividades equiparables. $\mathrm{Y}$ en este sentido, por otra parte, constituían otra vía para impulsar, y disciplinar, la agregación corporativa, a uno y otro lado de la línea de clase. Condición que además limitaba las posibilidades de hacer acuerdos particulares por empresas. En este sentido la Ley 14250 vino a normalizar ex post, un conjunto de situaciones sobre las cuales habían ido construyéndose mecanismos de regulación en la práctica cotidiana de los estrados, que resolviendo sobre individuos particulares irían fijando normas que actuaban finalmente en la defensa jurídica del interés colectivo.

\section{Consideraciones finales}

Aun cuando las preocupaciones por la regulación del mundo del trabajo reconocían ya para la década del cuarenta en el país un largo recorrido, el peronismo

${ }^{46}$ Sentencia $\mathrm{N}^{\circ} 38$, Francisco Fanoy y Juan Antonio García contra Sucesión José Figuerola, APJPSF, Libro de sentencias, Tomo I, 1949-1951, 12/05/1950, folios 63 y 64. 
introdujo un fuerte gesto de ruptura respecto de su expansión no solo en las instancias administrativas sino además en la implementación de la justicia del trabajo en todo el territorio argentino. En este sentido como hemos visto la opción del Poder Ejecutivo nacional por la resolución pragmática de los conflictos y demandas, antes que el fortalecimiento de un ordenamiento regulado por un código laboral común y una justicia laboral federal, creó un sistema doblemente híbrido. Por una parte, tribunales provinciales que aplicaban leyes nacionales y viceversa, agencias estatales federales que supervisaban el cumplimiento de la legislación provincial. Pero, por otra, abría un terreno nebuloso en la articulación entre el Poder Judicial y el administrador; y entre el cariz individual de los litigios en los estrados y el carácter colectivo de las disputas laborales. Una de las modulaciones de estas indefiniciones tuvo su escenario en los conflictos que derivaron de los marcos regulatorios implementados para la negociación de convenios colectivos. Ya que, si bien las agencias administrativas estatales eran las encargadas de reglar los protocolos de negociación colectiva, conciliación y arbitraje; quedaba abierta la vía judicial para impugnarla. La ausencia de una ley sobre convenios colectivos y su régimen de aplicación, recién sancionada en 1953, dejó abierto un campo de disputas sobre diversos aspectos -jurisdicciones de aplicación, cualidades jurídicas de los actores, reparticiones ejecutoras, capacidades de las comisiones paritarias, entre otros - que darían espacio a resistencias y cuestionamientos. Como hemos visto a partir de la indagación respecto al desempeño del tribunal laboral rosarino en sus primeros años de funcionamiento, una buena parte de estas estrategias de impugnación tendrían su escenario en los estrados del trabajo: expresando la conflictividad derivada del corrimiento de las rutinas de negociación colectiva del ámbito local al nacional; las disputas por el control de las condiciones de trabajo al interior de cada unidad productiva; o las estrategias de resistencia de categorías desprotegidas de trabajadores en un modo menos visible pero no por ello menos combatiente que el de la conflictividad que ganaba la calle.

En este registro los tribunales del trabajo, en su funcionamiento cotidiano, ofrecen además de un mirador diferente para analizar el rol mediador del Estado o el propio conflicto, un corpus estratégico para situar el papel de lo social en las relaciones discursivas que construyen mecanismos de identificación en el mundo del trabajo. En tanto las sentencias se erigen como campo de comprobación de un complejo proceso de construcción lingüística de «las experiencias» de clase; y en ese 
sentido abren una ventana para indagar sobre el impacto de estos espacios en dos principales dimensiones: como poderosas herramientas de construcción de identidades; a la par que de disciplinamiento y de encauzamiento de la conflictividad social. En este registro, de las sentencias analizadas pueden derivarse varias conclusiones. En primer lugar, en ellas se erige una noción de trabajo cuyo elemento constitutivo es la relación salarial-muchas veces identificado como lazo económico desigual- entre patronos y trabajadores; quedando otros criterios en los márgenes como las escalas de los establecimientos, las particularidades locales y sectoriales, el carácter manual o no de la labor, el grado de mecanización y complejidad de la actividad económica, etc.-. En segundo lugar, y en relación con esto, ambos polos son instituidos en sujetos de derechos, no en su individualidad, sino, como señalaba el juez Ruprecht, en tanto parte de una «colectividad» o corporación reconocida por el Estado; las cuales se presentaban, adicionalmente, con capacidades desiguales de negociación, situación que la ley proponía equilibrar. De allí la naturaleza «social» del contrato de trabajo, noción sobre la cual se asentaba todo el entramado de la legislación laboral que aplicaban los estrados. En ese sentido, y en tercer lugar, la discursividad judicial reforzará, a pesar de pronunciarse en el papel sobre conflictos individuales, la construcción de sujetos colectivos ubicados ideológicamente -si bien no siempre desde el punto de vista socioeconómico- en las antípodas: por una parte una «clase trabajadora», constituida sobre presupuestos de homogeneidad-en torno a un nosotros masculino, corporativo y nacional-,y una «clase patronal» que también, en su condición de proveedora de trabajo, va perdiendo atributos particulares en el lenguaje de las sentencias.

\section{Bibliografía}

Ascolani, Adrián, El Sindicalismo rural en la Argentina. De la resistencia clasista a la comunidad organizada (1928-1952). Bernal, Universidad Nacional de Quilmes, 2009.

Bacolla, Natacha, «Nuevas capacidades estatales para una sociedad transformada. Instituciones y políticas sanitarias en la provincia de Santa Fe, primera mitad del siglo XX», en Trabajos y comunicaciones, $\mathrm{N}^{\circ}$ 44, UNLP, 2016.

- «Política, administración y gestión en el peronismo santafesino, 1946-1955», en MACOR, D. \& TCACH, C. (eds.), La invención del peronismo en el interior del país, Santa Fe, Ediciones UNL, 2003. 
- «Debates, prácticas políticas y reforma institucional en la entreguerras. Un análisis desde el caso santafesino», en LEONI, M.S. y SOLÍS CARNICER, M.M., La política en los espacios subnacionales. Provincias y territorios en el nordeste argentino (18801955), Rosario, Prohistoria, 2012.

- «El lugar del Estado en la construcción de identidades políticas. Regulaciones del trabajo y la construcción del peronismo en la provincia de Santa Fe», en Revista de Historia Americana y Argentina, vol. 53, $\mathrm{N}^{\circ}$ 2, Mendoza, $\mathrm{UNCu}, 2018,161-191$.

- «Legislar el trabajo. Notas acerca de la construcción de un saber jurídico sobre el trabajo en Argentina: el caso de la Universidad del Litoral». En Nuevo Mundo Mundos Nuevos [en línea], Questions du temps présent, 2018. Recuperado a partir de: http://journals.openedition.org/nuevomundo/71889.

Barandiarán, Luciano, «Las estrategias de los trabajadores rurales ante la justicia: Azul, 1930-1945», en Anuario del Centro de Estudios Históricos Profesor Carlos A. Segreti, Córdoba, vol. vII, 2007.

Chatriot, Alain, Join-Lambert, Odile y Viet, Vincent, Les politiques du Travail (19062006) : acteurs, institutions, réseaux, Rennes, Presses Universitaires de Rennes, 2006.

Del Campo, Hugo, Sindicalismo y peronismo. Los comienzos de un vínculo perdurable, Buenos Aires, Clacso, 1983.

Doyon, Luise, Perón y los trabajadores. Los orígenes del sindicalismo peronista, 19431955, Buenos Aires, Siglo Veintiuno Editores, 2006.

Fink, Leon y Palacio, Juan Manuel (eds.), Labour Justice across the Americas, Illinois, University of Illinois Press, 2018.

Gaudio, Ricardo y Pilone, Jorge, «Estado y relaciones laborales en el período previo al surgimiento del peronismo, 1935-1943», en Desarrollo Económico, No 94, 1984, 237.

Genoud, Héctor, «La competencia de los tribunales del trabajo en la legislación provincial», en Gaceta del Trabajo, $\mathrm{N}^{\circ}$ 9, abril-junio de 1949, Buenos Aires: Editorial Bibliográfica Argentina.

Korol, Juan Carlos, «La economía», en CATTARUZZA, A. (dir.), Crisis económica, avance del Estado e incertidumbre política (1930-1943), Tomo VII, Buenos Aires, Sudamericana, 2001.

Lattuada, Mario, La política agraria peronista (1943-1983), 2 tomos, Buenos Aires, CEAL, 1986.

Lobato, Mirta y Suriano, Juan (comps.), La sociedad del trabajo. Las instituciones laborales en la Argentina (1900-1955), Buenos Aires, Edhasa, 2014.

Luciani, María Paula (2014), «La etapa formativa de la Secretaría de Trabajo y Previsión (1943-1946): primeros pasos organizativos y figuras relevantes», en Anuario del Instituto de Historia Argentina, $\mathrm{N}^{\mathrm{o}}$ 14. Recuperado a partir de: http://www.anuarioiha.fahce.unlp.edu.ar/article/view/IHAn14a01.

- De la Secretaría al Ministerio de Trabajo y Previsión: transformación estatal, elencos y frentes de intervención durante el primer peronismo, Unsam/Idaes, Tesis de doctorado, 2016.

Lvovich, Daniel y Suriano, Juan, Las políticas sociales en perspectiva histórica. Argentina 1870-1952, Buenos Aires, Prometeo, 2006. 
Nieto, Agustín, «Conflictividad obrera en el terreno de la justicia laboral. La experiencia de las obreras/os del pescado, 1950-1955», en AA.VV., Los puertos y su gente: pasado, presente y porvenir, Mar del Plata, GESmar, 2011, 117-128.

Palacio, Juan Manuel, «El grito en el cielo. La polémica gestación de los tribunales del trabajo en Argentina», en: Estudios Sociales, N ${ }^{\circ} 48,1 .^{\text {er }}$ semestre de 2015, Santa Fe, UNL, p. 61.

- La justicia peronista, Buenos Aires, Siglo Veintiuno Editores, Buenos Aires, 2018.

- La paz del trigo, Buenos Aires, Edhasa, 2013.

Piazzesi, Susana, Conservadores en provincia. El iriondismo santafesino, 1937-1943, Santa Fe, Ediciones UNL, 2009.

Plotkin, Mariano y Zimmerman, Eduardo (comps.), Saberes del Estado, Buenos Aires, Edhasa, 2012.

Prol, Mercedes, «El Partido Peronista en Santa Fe y el movimiento obrero. Relaciones de poder, acuerdos y conflictos, 1946-1955», en Historia Regional, Sección Historia, ISP $\mathrm{N}^{\mathrm{O}} 3$, año XXVI, $\mathrm{N}^{\mathrm{O}} 31,2013,9-26$.

- Ramacciotti, Karina, «De la culpa al seguro. La ley de accidentes de trabajo, Argentina 1915-1955», en Revista Mundos do Trabalho, vol. 3, No 5, enero-junio de 2011, 266284.

- «Presentación al dossier: Ley de Accidentes de Trabajo y Enfermedades profesionales», en: Estudios Sociales, N ${ }^{\circ}$ 49, Santa Fe: UNL, 2015, 85-93.

Schojölden, Line, Suing for Justice: Labor and the Courts in Argentina, 190o-1943, Berkeley, Tesis de Doctorado, Universidad de California, 2002.

Simonassi, Silvia «Empresarios, conflictividad obrera y negociación colectiva durante el primer peronismo en la ciudad de Rosario», en Nuevo Mundo. Mundos Nuevos, [en línea] Questions du temps présent, puesto en línea 07/2016, última visita: 04/2017. URL: http://nuevomundo.revues.org/69461.

Soprano, Germán, «El Departamento Nacional del Trabajo y su Proyecto de Regulación Estatal de la Relación Capital-Trabajo en Argentina: 1907-1943», en Panettieri, José (comp.), Argentina: trabajadores entre dos guerras, Buenos Aires, Eudeba, 2000.

Stagnaro, Andrés, Y nació un derecho. Los tribunales del trabajo en la provincia de Buenos Aires, Buenos Aires, Biblos, 2018.

Stedman Jones, Gareth, Lenguajes de clase. Estudios sobre la historia de la clase obrera inglesa, Madrid, Siglo Veintiuno Editores, 1989.

Suriano, Juan (comp.), La cuestión social en Argentina 1870-1943, Buenos Aires, Editorial La Colmena, 2000.

Thompson, E.P., Costumbres en común, Barcelona, Crítica, 1995.

- Los orígenes de la ley negra. Un episodio de la historia criminal inglesa, Buenos Aires, Siglo Veintiuno Editores, 2010.

Torre, Juan Carlos, La vieja guardia sindical y Perón. Sobre los orígenes del peronismo, Buenos Aires, Sudamericana, 1990.

Zimmermann, Eduardo, Los liberales reformistas. La cuestión social en la Argentina, 1890-1916, Buenos Aires, Sudamericana, 1995. 


\section{Fuentes:}

Astesano, Eduardo, «Convenios colectivos. Estudio de los convenios inscriptos en la Delegación Regional Rosario», en Revista de la Federación Gremial del Comercio y la Industria, $\mathrm{N}^{\mathrm{O}}$ 225, 06/1946, 235-242.

Ruprecht, Alfredo, "El fuero del trabajo en la provincia de Santa Fe», en Gaceta del Trabajo, $\mathrm{N}^{\circ}$ 8, enero-marzo de 1949, Buenos Aires, Editorial Bibliográfica Argentina.

Tissembaum, Mariano, «La legislación del trabajo y la cuestión jurisdiccional», en Gaceta del Trabajo, $\mathrm{N}^{\circ} 1$, abril-junio de 1945, Buenos Aires, Editorial Bibliográfica Argentina.

Archivo del Poder Judicial Provincia de Santa Fe, Libro de resoluciones, Cámara de Apelaciones del Trabajo, Segunda Circunscripción, Tomo I 1949-195.

Archivo del Poder Judicial Provincia de Santa Fe, Libros de sentencias, Juzgado de $1^{\circ}$ nominación, Segunda circunscripción, Rosario (1949-1957).

Crónica Mensual de la Secretaría de Trabajo y Previsión, 1945-1950.

Censo Nacional de Población 1960, Tomo IV Zona Central: Córdoba y Santa Fe.

\section{Prensa:}

El Litoral, Santa Fe (1945-1955)

El Orden, Santa Fe (1945-1955)

Tribuna, Rosario (1945-1955)

La Capital, Rosario (1945-1955) 